\title{
Excellent crystalline silicon surface passivation by amorphous silicon irrespective of the technique used for chemical vapor deposition
}

\author{
Jan-Willem A. Schüttauf, ${ }^{\text {a) }}$ Karine H. M. van der Werf, Inge M. Kielen, \\ Wilfried G. J. H. M. van Sark, Jatindra K. Rath, and Ruud E. I. Schropp \\ Debye Institute for Nanomaterials Science, Nanophotonics-Physics of Devices, Utrecht University, \\ Princetonplein 5, 3584 CC Utrecht, The Netherlands
}

(Received 1 February 2011; accepted 28 March 2011; published online 15 April 2011)

\begin{abstract}
Crystalline silicon surface passivation by amorphous silicon deposited by three different chemical vapor deposition $(\mathrm{CVD})$ techniques at low $\left(\mathrm{T} \sim 130{ }^{\circ} \mathrm{C}\right)$ temperatures is compared. For all three techniques, surface recombination velocities (SRVs) are reduced by two orders of magnitude after prolonged thermal annealing at $200{ }^{\circ} \mathrm{C}$. This reduction correlates with a decreased dangling bond density at the amorphous-crystalline interface, indicating that dangling bond saturation is the predominant mechanism. All three deposition methods yield excellent surface passivation. For a-Si:H layers deposited by radio frequency plasma enhanced CVD, we obtain outstanding carrier lifetimes of $10.3 \mathrm{~ms}$, corresponding to SRVs below $1.32 \mathrm{~cm} / \mathrm{s}$. (C) 2011 American Institute of Physics. [doi:10.1063/1.3579540]
\end{abstract}

Surface passivation is a key requirement in optimizing the performance of several types of crystalline silicon $(\mathrm{c}-\mathrm{Si})$ based solar cells. Various materials have been studied for this purpose, such as thermally grown silicon dioxide $\left(\mathrm{SiO}_{2}\right),{ }^{1}$ aluminum oxide $\left(\mathrm{Al}_{2} \mathrm{O}_{3}\right),{ }^{2}$, silicon nitride $\left(\mathrm{SiN}_{\mathrm{x}}\right),{ }^{3,4}$ amorphous silicon oxides $\left(\mathrm{a}-\mathrm{SiO}_{\mathrm{x}}\right),{ }^{5,6}$ amorphous silicon carbide $\left(\mathrm{a}-\mathrm{SiC}_{\mathrm{x}}\right),{ }^{7,8}$ as well as hydrogenated amorphous silicon $(\mathrm{a}-\mathrm{Si}: \mathrm{H}){ }^{9-12}$ Furthermore, excellent results on combined layer stacks of these materials have been reported, such as for stacks consisting of a-Si:H and $\mathrm{SiN}_{\mathrm{x}}$ (Refs. 13 and 14) and for thermal $\mathrm{SiO}_{2} / \mathrm{SiN}_{\mathrm{x}}$.

Especially for silicon heterojunction solar cells, ${ }^{16-19}$ a-Si:H is still the best material due to its excellent passivation properties that can be obtained at low processing temperatures. Here we present a comparison of the quality of surface passivation of c-Si wafers by a-Si:H layers deposited by three different deposition techniques; i.e., standard radio frequency plasma-enhanced chemical vapor deposition (rf PECVD) at $13.56 \mathrm{MHz}$, very high frequency PECVD (VHF PECVD) at $50 \mathrm{MHz}$ and hot-wire CVD (HWCVD). Comparing these different fabrication methods is of interest since the reduced ion bombardment in VHF PECVD and the lack of ion bombardment in HWCVD compared to standard rf PECVD (Ref. 20) are thought to be advantageous for the quality of c-Si surface passivation due to the reduction in ion impact defect creation at the a-Si:H/a-Si interface. ${ }^{21}$ On the other hand, a comparison of the bulk properties of the a-Si:H films made by these three techniques shows significant differences in structural disorder. ${ }^{22}$

De Wolf et al. ${ }^{10}$ have shown that long term annealing has a great influence on the minority carrier lifetime of c-Si wafers passivated by intrinsic a-Si:H layers deposited at relatively low $\left(130-180^{\circ} \mathrm{C}\right)$ temperatures. For a-Si:H layers deposited at $130{ }^{\circ} \mathrm{C}$ by VHF PECVD, De Wolf et al. reported a minority carrier lifetime of only $12.2 \mu$ s, as measured directly after deposition. After annealing at $\mathrm{T}=180{ }^{\circ} \mathrm{C}$, however, this lifetime showed a drastic increase; exceeding

\footnotetext{
a) Author to whom correspondence should be addressed. Electronic mail: j.a.schuttauf@uu.nl.
}

$500 \mu \mathrm{s}$ after $1 \mathrm{~h}$ of annealing, and saturating at $4.4 \mathrm{~ms}$ after prolonged annealing. Annealing thus appeared crucial for obtaining high minority carrier lifetimes, as it enables the movement of hydrogen in the a-Si:H film toward the a-Si:H/ c-Si interface, which strongly reduces the dangling bond density at the interface. ${ }^{9-11}$ We investigate this phenomenon for a-Si:H passivation layers made by rf PECVD, VHF PECVD, and HWCVD.

We use $275 \mu \mathrm{m}$ thick n-type float zone (FZ) c-Si $\langle 100\rangle$ double sided mirror polished wafers $(\rho \sim 2.5-3 \Omega \mathrm{cm})$. Prior to a-Si:H deposition, the wafers are dipped in hydrofluoric acid (HF) $\left(1 \%\right.$ in $\left.\mathrm{H}_{2} \mathrm{O}\right)$ for 2 min. Next, approximately $50 \mathrm{~nm}$ thick a-Si:H layers are deposited on both sides of the c-Si wafer. Between the two depositions, the wafers are flipped in air, without performing a second HF dip. The rf PECVDs are performed at a power density of $30 \mathrm{~mW} / \mathrm{cm}^{2}$ and a pressure of 1.08 mbar, using pure $\mathrm{SiH}_{4}$. The VHF PECVDs are performed at a power density of $31 \mathrm{~mW} / \mathrm{cm}^{2}$ and a pressure of 0.16 mbar, using $\mathrm{SiH}_{4}$ and $\mathrm{H}_{2}$ at a flow ratio of 1:1. The HWCVDs are performed using pure $\mathrm{SiH}_{4}$ at a pressure of 0.005 mbar and a wire temperature of $1820^{\circ} \mathrm{C}$. We use Ta wires with a diameter of $0.3 \mathrm{~mm}$. All depositions are performed at a calibrated substrate temperature of $(130 \pm 5)^{\circ} \mathrm{C}$. After deposition, all samples are annealed at $200{ }^{\circ} \mathrm{C}$ in $\mathrm{N}_{2}$ ambient for various annealing times; 1,16 , and $100 \mathrm{~h}$. The minority carrier lifetimes are measured by means of the quasi steady-state photoconductance (QSSPC) method ${ }^{23}$ using the quasi transient mode and the generalized mode. ${ }^{24}$

Figure 1 shows the minority carrier lifetime and surface recombination velocity (SRV) values of all samples at an injection level of $10^{15} \mathrm{~cm}^{-3}$ after different anneal times. The as-deposited lifetime of all samples is in the range of several tenths of microseconds (34 $\mu$ s for rf PECVD, $43 \mu$ s for VHF PECVD, and $87 \mu$ s for HWCVD). Prolonged annealing leads to much higher lifetimes for all three types of layers, even exceeding $10 \mathrm{~ms}$ for the sample with a-Si:H films made by $\mathrm{rf}$ PECVD. This value $\left(\tau_{\mathrm{eff}}=10.3 \mathrm{~ms}\right)$ is among the best reported values ever for the used type of c-Si wafers passivated by a-Si:H films. In Fig. 2, the injection level de- 


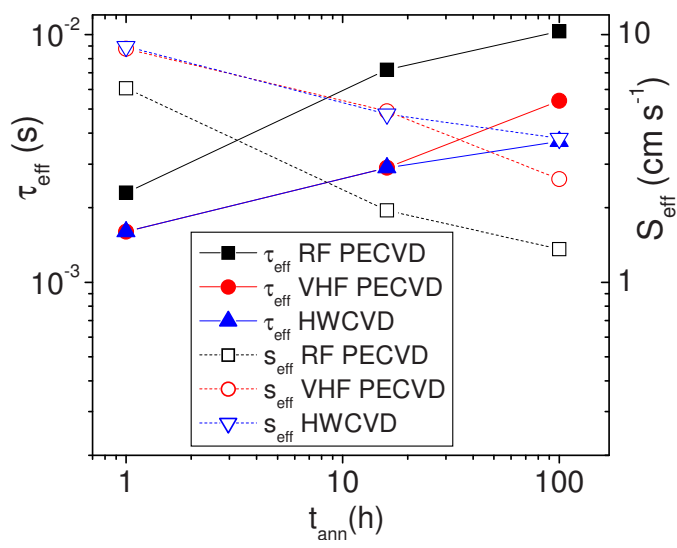

FIG. 1. (Color online) Effective minority carrier lifetimes and SRVs at an injection level of $10^{15} \mathrm{~cm}^{-3}$ of c-Si passivated by a-Si:H layers deposited by rf PECVD, VHF PECVD, and HWCVD. For the SRVs, infinite bulk lifetime is assumed.

pendence of the SRV for medium injection levels, most relevant for silicon heterojunction solar cell performance, is depicted. For VHF PECVD (5.4 ms) and HWCVD (3.7 ms) a-Si:H layers we also obtain excellent c-Si surface passivation. Koyama et al. ${ }^{14}$ obtained a value of $9.7 \mathrm{~ms}$ for $\mathrm{c}-\mathrm{Si}$ passivated by a layer stack consisting of a-Si:H/a-SiN $\mathrm{x}: \mathrm{H}$ deposited by HWCVD at $\mathrm{T} \leq 250{ }^{\circ} \mathrm{C}$, similar to our $\mathrm{rf}$ PECVD lifetime value. This implies that there is no clear preference in deposition method and that the role of ion bombardment at energies below $20 \mathrm{eV}$, typical for $\mathrm{rf}$ PECVD,${ }^{25}$ has no major influence at the low deposition temperatures we have used. ${ }^{26}$

In order to explain the excellent minority carrier lifetimes that can be obtained with a-Si:H, we distinguish different passivation mechanisms governing the lifetime characteristics and their changes upon prolonged thermal annealing. Generally, surface passivation is ascribed to two different phenomena, namely chemical passivation and field effect passivation. The former is caused by a reduction in defect states at the a-Si:H/c-Si interface, the latter by repulsion of minority charge carriers from the interface by fixed charges. Different models (e.g., the Olibet model ${ }^{9}$ and the Leendertz model ${ }^{27,28}$ ) have been proposed to fit injection level dependent SRV data to obtain values for the interface dangling bond density $\left(\mathrm{N}_{\mathrm{DB}}\right)$ and the fixed charge density $\left(\mathrm{Q}_{\mathrm{F}}\right)$. Our best minority carrier lifetime data are fitted to the Leendertz model. ${ }^{27,28}$ Especially for high injection levels,

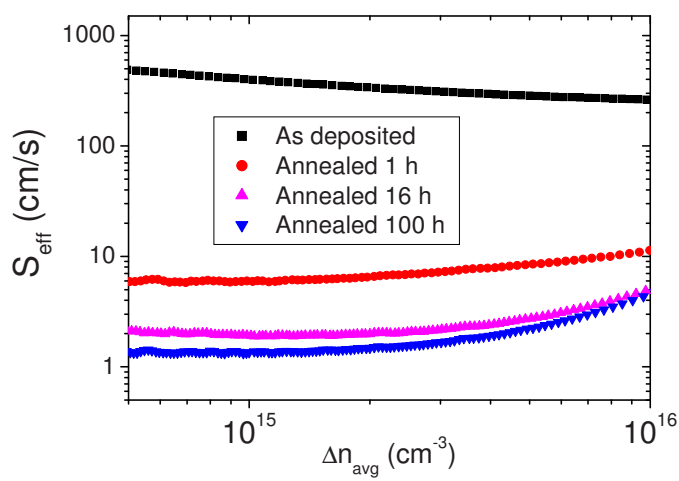

FIG. 2. (Color online) SRVs of c-Si passivated by a-Si:H layers deposited by standard rf PECVD for different anneal times for medium injection levels.

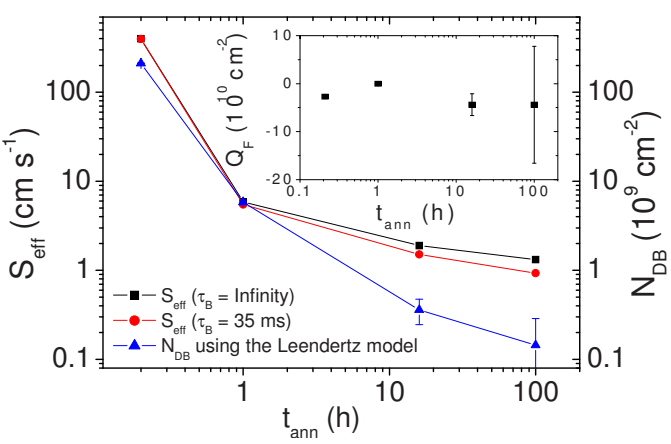

FIG. 3. (Color online) Calculated SRVs for c-Si passivated by rf PECVD a-Si:H layers for different anneal times, assuming infinite bulk lifetime (indicated by ) and a finite bulk lifetime of $35 \mathrm{~ms}$ (indicated by $\bullet$ ). Also shown is the dangling bond density as determined by fitting to the Leendertz model (Refs. 27 and 28). In the inset of the figure, the calculated fixed charge density is shown vs anneal time. For $\mathrm{N}_{\mathrm{DB}}$ and $\mathrm{Q}_{\mathrm{F}}$, error bars are shown. For the SRV data, the error bars are smaller than the data points and are therefore not explicitly shown.

Auger recombination also has to be taken into account. In the analysis in this letter, the model of Kerr and Cuevas is applied. ${ }^{29}$

In Fig. 3, the SRVs, as well as $\mathrm{N}_{\mathrm{DB}}$ values, are depicted versus the anneal time. These parameters obviously show the same trend. In the inset of Fig. 3, the fixed charge density is plotted against anneal time. No clear trend is observed for the fixed charge density. This indicates that the strongly reduced SRV is mainly caused by a reduction in $\mathrm{N}_{\mathrm{DB}}$ due to a saturation of dangling bonds by atomic hydrogen. The excellent c-Si surface passivation implies that the interface dangling bond density is in the order of only $10^{8} \mathrm{~cm}^{-2}$. The SRVs are calculated by two methods, i.e., assuming infinite bulk lifetime and assuming a bulk lifetime of $35 \mathrm{~ms}$, which is the highest reported experimental value for $\mathrm{FZ} \mathrm{c-Si}{ }^{30}$ With this latter approach, we calculate an extremely low SRV of $0.93 \mathrm{~cm} / \mathrm{s}$ at $10^{15} \mathrm{~cm}^{-3}$ for our data.

In summary, we have obtained very high quality surface passivation of c-Si wafers by a-Si:H films deposited by three different deposition methods. For a-Si:H films deposited by rf PECVD on c-Si substrates, we obtained an outstanding SRV of $1.32 \mathrm{~cm} / \mathrm{s}$ assuming an infinite bulk c-Si lifetime and $0.93 \mathrm{~cm} / \mathrm{s}$ assuming a finite bulk lifetime of $35 \mathrm{~ms}$. It is shown that prolonged annealing yields a strong increase in passivation quality irrespective of the deposition method for the a-Si:H layer. The increase in surface passivation quality is attributed to a strong reduction in defect states at the $\mathrm{a}-\mathrm{Si}: \mathrm{H} / \mathrm{c}-\mathrm{Si}$ interface, due to saturation of dangling bonds by atomic hydrogen. Modeling of our QSSPC data yields a dangling bond density in the order of $10^{8} \mathrm{~cm}^{-2}$ at the a-Si:H/ c-Si interface.

The authors would like to thank the European Commission for financial support (EU FP7 "Heterojunction Solar Cells based on a-Si c-Si" (HETSI), Grant Agreement No. 211821), Caspar Leendertz (Helmholtz Zentrum Berlin) for fitting our QSSPC data to his model and Martin Huijzer for depositions.

${ }^{1}$ M. J. Kerr and A. Cuevas, Semicond. Sci. Technol. 17, 35 (2002).

${ }^{2}$ B. Hoex, S. B. S. Heil, E. Langereis, M. C. M. van de Sanden, and W. M. M. Kessels, Appl. Phys. Lett. 89, 042112 (2006).

${ }^{3}$ M. J. Kerr, J. Schmidt, A. Cuevas, and J. H. Bultman, J. Appl. Phys. 89, 3821 (2001). 
${ }^{4}$ V. Verlaan, C. H. M. van der Werf, Z. S. Houweling, H. F. W. Dekkers, I. G. Romijn, A. W. Weeber, H. D. Goldbach, and R. E. I. Schropp, Prog. Photovoltaics 15, 563 (2007).

${ }^{5}$ H. Fujiwara, T. Kaneko, and M. Kondo, Appl. Phys. Lett. 91, 133508 (2007).

${ }^{6}$ T. Mueller, W. Duengen, R. Job, M. Scherff, and W. Fahrner, Amorphous and Polycrystalline Thin-Film Silicon Science and Technology, MRS Symposia Proceedings No. 989 (Materials Research Society, Pittsburgh, 2007), p. A05-02.

${ }^{7}$ I. Martín, M. Vetter, A. Orpella, C. Voz, J. Puigdollers, and R. Alcubilla, Appl. Phys. Lett. 81, 4461 (2002).

${ }^{8}$ C. Ehling, J. H. Werner, and M. B. Schubert, Phys. Status Solidi C 7, 1016 (2010).

${ }^{9}$ S. Olibet, E. Vallat-Sauvain, and C. Ballif, Phys. Rev. B 76, 035326 (2007).

${ }^{10}$ S. De Wolf, S. Olibet, and C. Ballif, Appl. Phys. Lett. 93, 032101 (2008).

${ }^{11}$ T. F. Schulze, H. N. Beushausen, C. Leendertz, A. Dobrich, B. Rech, and L. Korte, Appl. Phys. Lett. 96, 252102 (2010).

${ }^{12}$ J. Damon-Lacoste, L. Fesquet, S. Olibet, and C. Ballif, Thin Solid Films 517, 6401 (2009).

${ }^{13}$ S. Gatz, H. Plagwitz, P. P. Altermatt, B. Terheiden, and R. Brendel, Appl. Phys. Lett. 93, 173502 (2008)

${ }^{14}$ K. Koyama, K. Ohdaira, and H. Matsumura, Appl. Phys. Lett. 97, 082108 (2010).

${ }^{15}$ Y. Larionova, V. Mertens, N.-P. Harder, and R. Brendel, Appl. Phys. Lett. 96, 032105 (2010).

${ }^{16}$ Y. Tsunomura, Y. Yoshimine, M. Taguchi, T. Baba, T. Kinoshita, H. Kanno, H. Sakata, E. Maruyama, and M. Tanaka, Sol. Energy Mater. Sol. Cells 93, 670 (2009).

${ }^{17}$ Q. Wang, M. R. Page, E. Iwanicko, Y. Xu, L. Roybal, R. Bauer, B. To, H.-C. Yuan, A. Duda, F. Hasoon, Y. F. Yan, D. Levi, D. Meier, H. M.
Branz, and T. H. Wang, Appl. Phys. Lett. 96, 013507 (2010).

${ }^{18}$ A. Descoeudres, L. Barraud, R. Bartlome, G. Choong, S. De Wolf, F. Zicarelli, and C. Ballif, Appl. Phys. Lett. 97, 183505 (2010).

${ }^{19}$ B. Strahm, Y. Andrault, D. Baetzner, C. Guérin, N. Holmes, M. Kobas, D. Lachenal, B. Mendes, M. Tesfai, G. Wahli, F. Wuensch, A. Buechel, J. Mai, T. Schulze, and M. Vogt, Proceedings of 25th EU PVSEC, Valencia, Spain, 2010, p. 1286.

${ }^{20}$ R. E. I. Schropp and M. Zeman, Amorphous and Microcrystalline Silicon Solar Cells: Modeling, Materials and Device Technology (Kluwer Academic, Boston/Dordrecht/London, 1998)

${ }^{21}$ T. H. Wang, E. Iwaniczko, M. R. Page, Q. Wang, D. H. Levi, Y. Yan, Y. $\mathrm{Xu}$, and H. M. Branz, Amorphous and Nanocrystalline Silicon Science and Technology, MRS Symposia Proceedings No. 862 (Materials Research Society, Pittsburgh, 2005), p. A23.

${ }^{22}$ J. K. Rath, R. E. I. Schropp, P. Roca i Cabarocas, and F. D. Tichelaar, J. Non-Cryst. Solids 354, 2652 (2008).

${ }^{23}$ R. A. Sinton and A. Cuevas, Appl. Phys. Lett. 69, 2510 (1996).

${ }^{24}$ H. Nagel, C. Berge, and A. G. Aberle, J. Appl. Phys. 86, 6218 (1999).

${ }^{25}$ E. A. G. Hamers, W. G. J. H. M. van Sark, J. Bezemer, H. Meiling, and W. F. van der Weg, J. Non-Cryst. Solids 226, 205 (1998).

${ }^{26}$ J. K. Rath, M. M. de Jong, A. Verkerk, M. Brinza, and R. E. I. Schropp, Amorphous and Polycrystalline Thin Film Silicon Science and Technology, MRS Symposia Proceedings No. 1153 (Materials Research Society, Pittsburgh, 2009), p. A22.

${ }^{27}$ C. Leendertz, R. Stangl, T. F. Schulze, M. Schmidt, and L. Korte, Phys. Status Solidi C 7, 1005 (2010).

${ }^{28}$ C. Leendertz, N. Mingirulli, T. F. Schulze, J. P. Kleider, B. Rech, and L. Korte, Proceedings of 25th EU PVSEC, Valencia, Spain, 2010, p. 1377.

${ }^{29}$ M. J. Kerr and A. Cuevas, J. Appl. Phys. 91, 2473 (2002).

${ }^{30}$ E. Yablonovitch and T. Gmitter, Appl. Phys. Lett. 49, 587 (1986). 